\title{
The Szymkowiak's over-expanded cycle in the rocker engine with the variable compression ratio - kinematics
}

ARTICLE INFO

Received: 10 August 2021

Revised: 31 August 2021

Accepted: 18 October 2021

Available online: 30 October 2021
The article discusses the innovative concept of the over-expanded thermodynamic cycle, the author of which is the Polish engineer-designer Mirostaw Szymkowiak. This cycle is realized on the basis of a new and innovative, previously unknown design, of a piston-crankshaft linkage mechanism with the aid of an additional element known as a rocker arm. Additionally, the proposed mechanism allows for a smooth change of the compression/expansion ratio of the engine during its operation. In the beginning, the earlier conceptions of the rocker engine developed by Szymkowiak were presented, and then the main construction assumptions and kinematic calculations were described. It was confirmed, that the developed linkage has big potential in improving the engine's thermal efficiency by approximately $12 \%$ relative. Additionally, it significantly reduces the exhaust gas pressure, when the exhaust valve is opened, therefore, contributes to the reduction of the noise emitted by the engine.

Key words: rocker, engine, linkage, over-expanded cycle, variable expansion/compression ratio

This is an open access article under the CC BY license (http://creativecommons.org/licenses/BY/4.0/)

\section{Introduction}

Several intensive measures have been taken focusing on issues related to combustion and engine design. Research is conducted on the improvement of the engine overall efficiency and reduction of exhaust emissions. It is carried out on various levels, including the search for new kinematic solutions that enable the variable compression ratio and over-expanded cycle implementations into the engine. As a result, several solutions were invented to convert the reciprocating motion of the piston into the rotary motion of the crankshaft [1-3].

One of these kinematic mechanisms is presented in the article. Its inventor is the Polish engineer Mirosław Szymkowiak. Szymkowiak has been working on his solutions for years [3] and as a result, he has achieved several improvements. The main feature of the developed mechanism is the rocker arm that connects two connecting rods: the first one is located between the piston and the rocker arm, the second one - between the rocker arm and the crankshaft, respectively. In the past (1950s and 1960s) the engine equipped with a rocker arm and two connecting rods was the Commer TS3 2-stroke diesel engine built by Tilling-Stevens in the Rootes group [1, 2]. Each cylinder contained two pistons positioned horizontally opposite each other and moving opposite each other as depicted in Fig. 1. This engine was launched into mass production and installed in trucks.

The concept of applying the rocker as the element for combining combustion forces from 4 pistons into a single crank of the crankshaft was the main idea of this design (Fig. 3 and 4). Hence, the mechanism examined in the paper is novel work and is under intellectual protection. Unlike the two-stroke Commer engine, the rocker engine presented in the paper is four-stroke one. The mechanism provides possibilities of obtaining various mean piston speeds at constant crankshaft rotational speed because the piston stroke is independent of the crank length. Additionally, the mechanism provides possibility of change in both the com- pression and expansion ratio. This concept refers to the solution presented by Rychter and Teodorczyk [4, 5]. The mechanism VR/VL, which they proposed, applies a variable ratio of the length of the crank to the connecting rod in order to change the compression ratio.

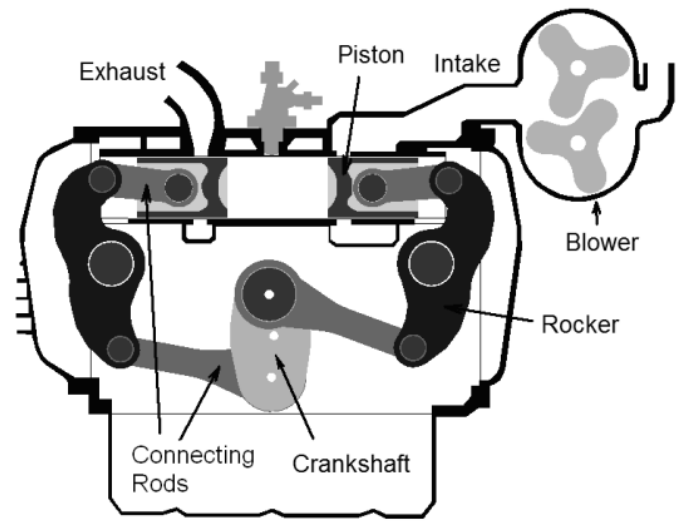

Fig. 1. Kinematic linkage in the rocker Commer engine $[1,2]$

As depicted in Fig. 2 the rocker in this conception connects a piston and transfers motion with aid of the main connecting rod into the crankshaft. In further analysis the rocker is equipped with four pins separately connecting each piston to the rocker as shown in Fig. 3 and 4.

Kozak [6] presented a closer qualitative analysis of a crank-and-rocker piston mechanism. In comparison to a conventional piston assembly, this mechanism is composed of additional elements called rockers. A higher number of elements allows better functional flexibility of the mechanism, particularly in terms of the piston motion. As discussed by Kozak, this feature can be used to control the course of the engine torque, the heat losses to the cooling system, the reduction of the piston pressure on the cylinder liners (friction and mechanical losses) as well as variation of the compression ratio easily performed during engine 
operation. As Magryta recommended [7], the finite element methods and analytical kinematics analysis can be successfully applied into the motion and stress analysis for the piston-conrod-crankshaft mechanism.

The first conception of the rocker engine invented by M. Szymkowiak is depicted in Fig. 2.
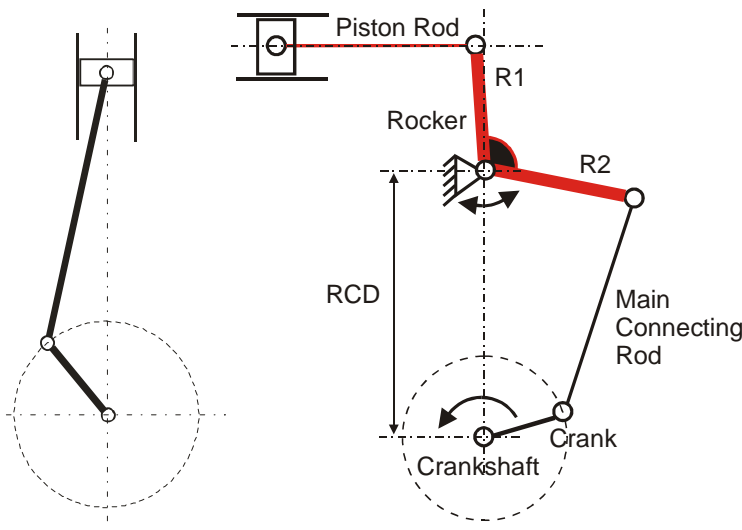

Fig. 2. Kinematic diagram of a) classic linkage, b) first conception of the rocker engine

On the basis of the construction presented in Fig. 2, Mr. Szymkowiak worked out the multi-cylinder engine with kinematic linkage presented in Fig. 3 and its 3-D presentation in Fig. 4. As seen in Fig. 4, the 8-cylinder engine features its compactness and relatively short crankshaft length.

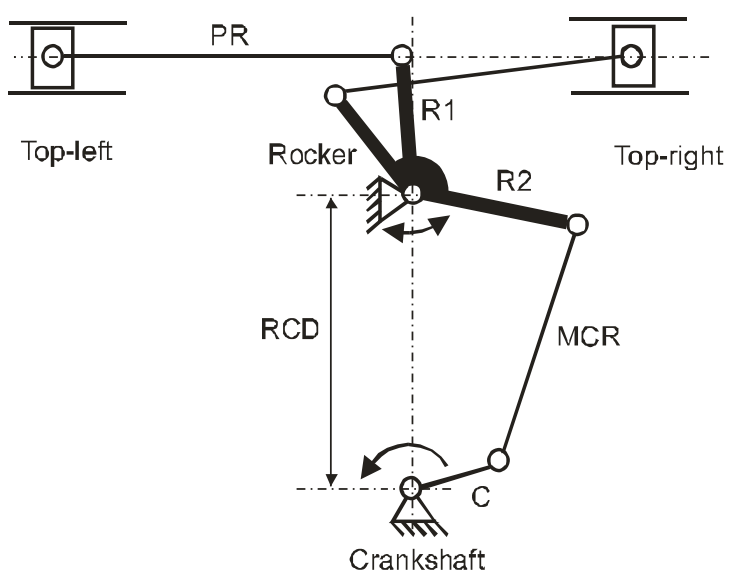

Fig. 3. Kinematic diagram of the 2-cylinder rocker engine

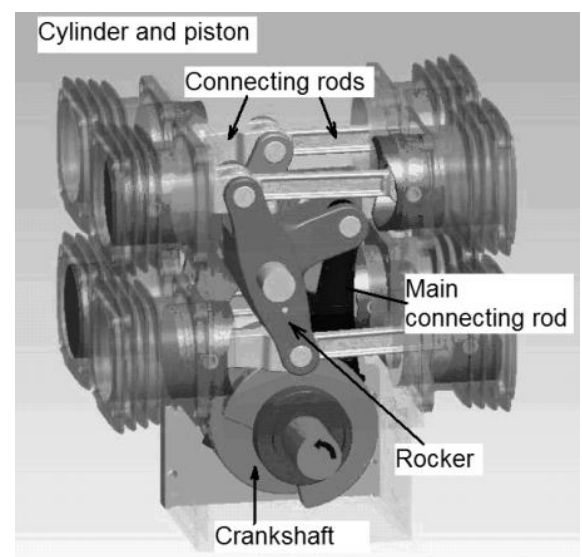

Fig. 4. Conception of the 8-cylinder rocker engine
Next modifications were done towards cylinders' positions. From their horizontally oriented locations the cylinders were oriented vertically as depicted in Fig. 5a.

a)

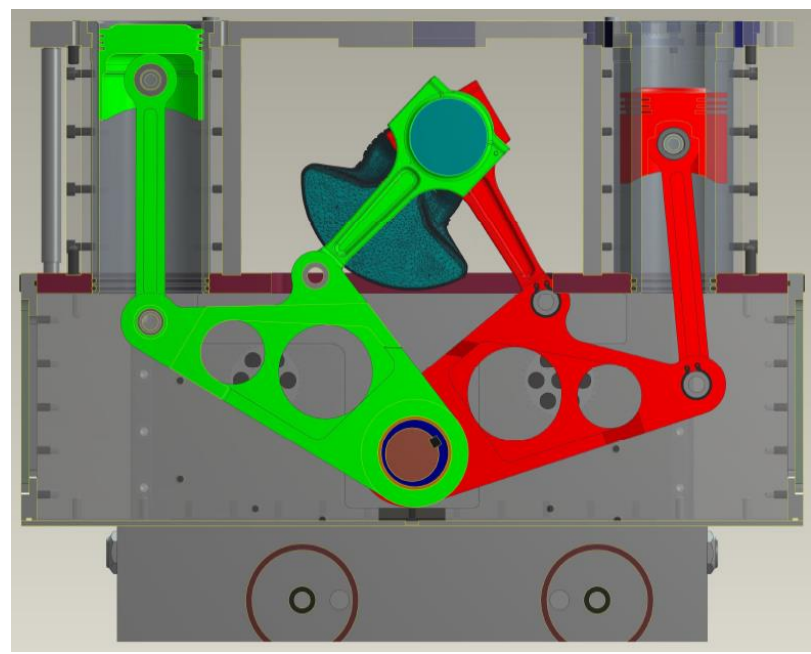

b)

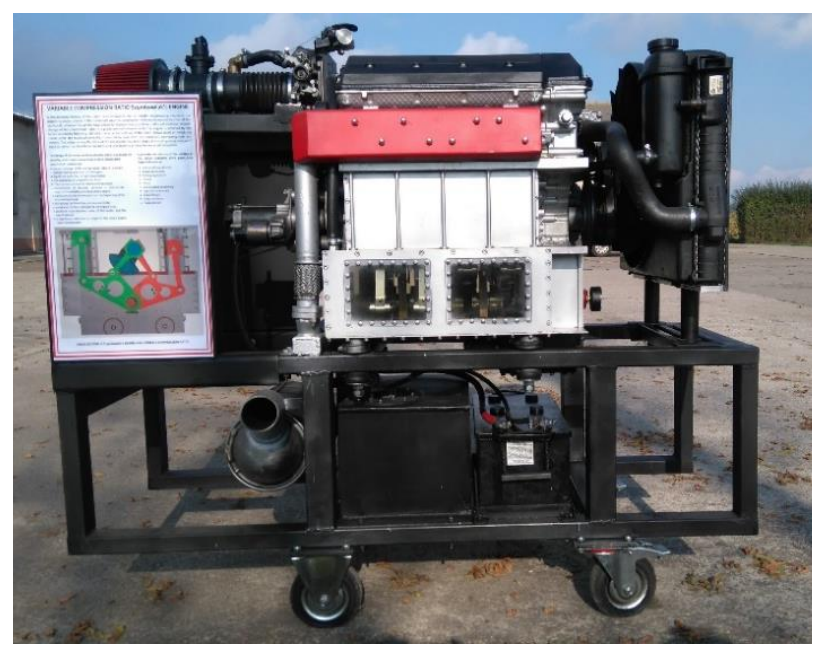

Fig. 5. a) Model and b) prototype of the 8-cylinder rocker engine

Based on this conception the 8-cylinder engine was built (Fig. 5b) and tested. During the engine preliminary tests, the proper engine work without any malfunction was confirmed. The design of the rocker crank mechanism allows to obtain benefits as follows:

- change of the compression and expansion ratio in a simple way during operation of the engine,

- significant reduction in fuel consumption,

- the possibility of using various fuels,

- the asymmetry in compression and expansion,

- significant increase in torque from the beginning of the expansion process,

- non-zero torque at the TDC,

- piston-cylinder sleeve force is several times lower in comparison to the classic solutions, that leads to a decrease in friction wear, so increases overall efficiency, and increases the life of the piston and cylinder, 
- excellent ratio of mass to the engine swept volume,

- a significant reduction of height in the marine engine (a slider is an unnecessary item).

The proposed construction makes building the longstroke engine without drawbacks associated with the classic solution.

A characteristic feature of the engine is an innovative way to transfer the reciprocating motion of the pistons to the rotary motion of the crankshaft. The crankshaft in combination with its innovative location between the cylinder rows allows for features inaccessible to traditional solutions. The design is very flexible and anyone has a much greater amount of slack variables than in traditional solutions and can use them to achieve the required parameters. It is worth of emphasizing that the proposed linkages would be particularly useful for engines with long strokes working at relatively high loads (CHP units, marine engines, harvesting machines, mining machinery, train engine as well as lorries, off-road military vehicles etc.).

\section{Engine with variable compression ratio and over-expanded cycle - the conception}

Several studies realized by Mr. M. Szymkowiak occurred fruitful in working out the conception and finally the engine, which characterizes by both variable compression ratio and over-expanded cycle. The schematic diagram is shown in Fig. 6. As depicted, the mechanism consists of the following parts:

- piston (1),

- connecting rods (2) and (5),

- $\operatorname{rocker}(3)$,

- eccentricity - eccentric crank (4),

- crankshaft (6).

A specific feature of this linkage is the eccentric crank, which rotates in the same direction as the crankshaft rotates, but with a speed twice lower than the engine crankshaft speed $n_{s}$. The eccentricity notion, used in further discussion, is the length of this eccentric crank. The rocker is swingingly mounted to this crank.

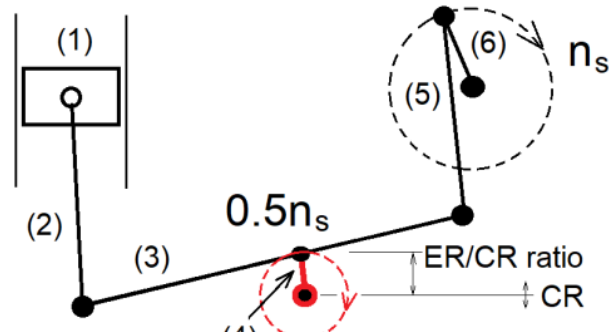

(4)

Fig. 6. Piston-crankshaft linkage of the new conception of the rocker engine

The main dimensions of the linkage and the engine are as follows:

- rocker (3) length: $220 \mathrm{~mm}$,

- connecting rod (2) length: $162.5 \mathrm{~mm}$,

- connecting rod (5) length: $143 \mathrm{~mm}$,

- eccentric crank (4) length: varied from 0 till $20 \mathrm{~mm}$,

- crank length (6): $32.9 \mathrm{~mm}$,

- single cylinder displacement: $376 \mathrm{ccm}$,
- cylinder bore: $60 \mathrm{~mm}$,

- maximum piston stroke: $133.2 \mathrm{~mm}$,

- compression ratio: 9.5 ,

- proposed fuel: regular gasoline.

As shown in Fig. 6, the compression and expansion ratios can be changed by changing the vertical position of the eccentric crank rotational axis. The construction of the proposed mechanism allows change of this parameter under engine work. The compression ratio can vary from 7 to 14 .

The CAD model of this engine is presented in Fig. 7. Among others, horizontal lines mark TDC and BDC of the pistons.

a)

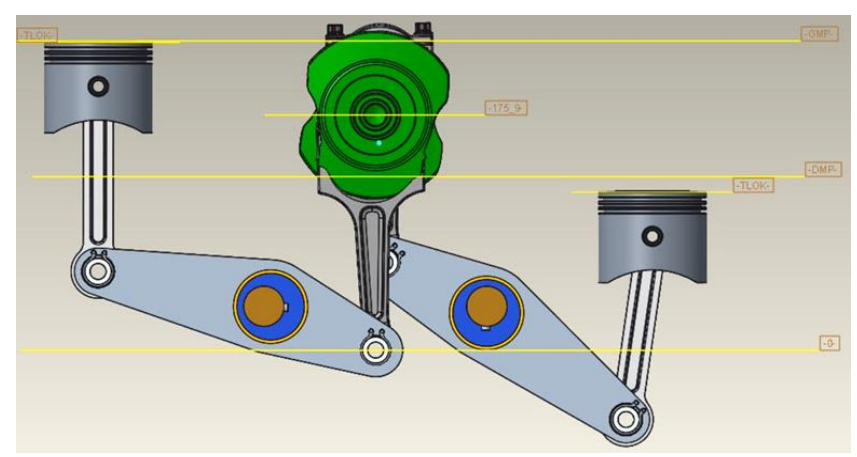

b)

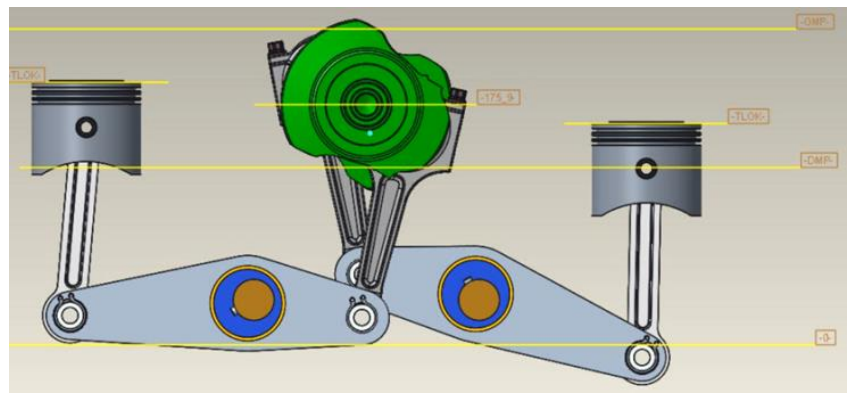

c)

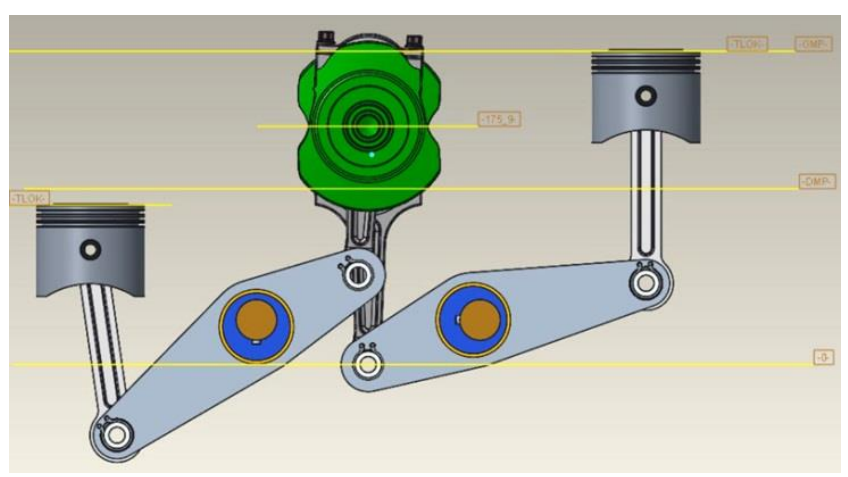

Fig. 7. New conception in various crankshaft angular positions: a) $0 \mathrm{CA}$ deg, b) $120 \mathrm{CA}$ deg, c) $180 \mathrm{CA}$ deg

\section{Results and discussion}

Kinematic analysis was realized with the aid of Matlab/ Simulink software. Hence, the kinematic linkage was directly simulated in this computational environment without any mathematical models. Figure 8 shows the piston dis- 
tance profile over the crank angle for a 4-stroke engine. The idea for realizing the over-expanded thermodynamic cycle is based on variable piston stroke, which is shorter at the compression process (denoted as the compression stroke in Fig. 8), and longer at the expansion one. As seen, the compression stroke expressed in crank angle is around $159 \mathrm{CA}$ deg, while the expansion stroke is $213 \mathrm{CA}$ deg. Hence, additional expansion work is generated, that creates additional power benefit on the engine crankshaft. Piston position at $0 \mathrm{~mm}$ corresponds to its TDC location. The negative numbers result from positioning of piston motion in the coordinating system in the Matlab modelling software. The piston profile was determined for the eccentricity of 15 $\mathrm{mm}$. Other piston distance profiles vs. crank angle for various eccentricities are depicted in Fig. 9.

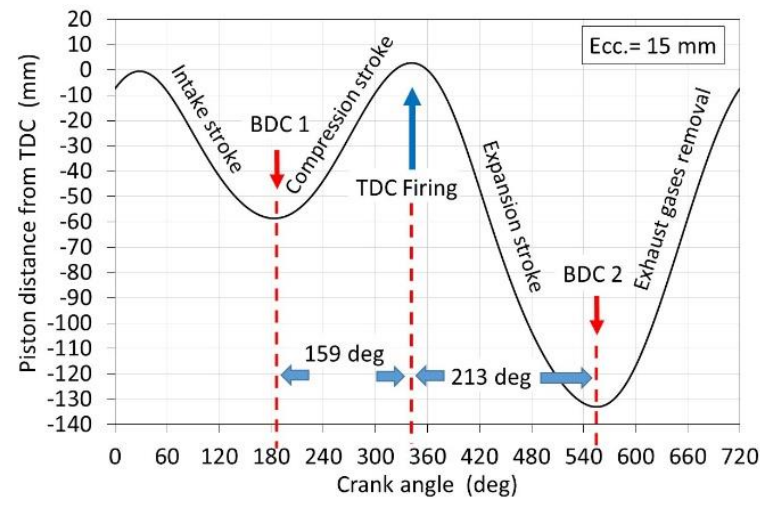

Fig. 8. Piston distance from TDC

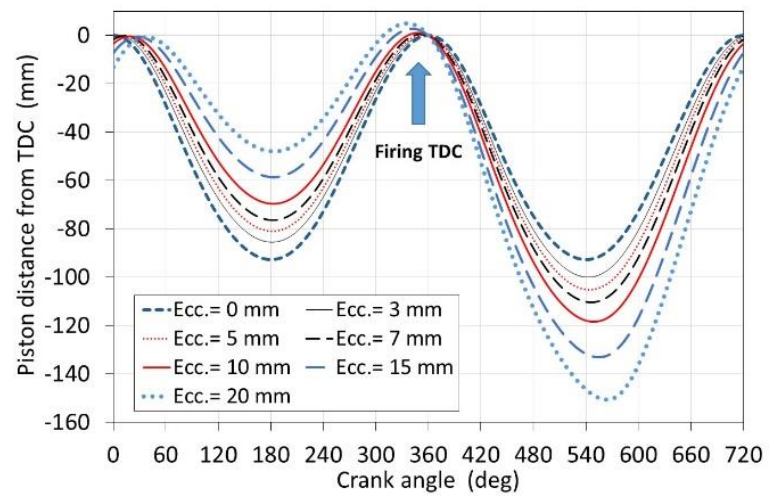

Fig. 9. Piston distance from TDC for various eccentricities

As concluded from Fig. 9, higher eccentricity makes the compression stroke shorter and lengthens the expansion stroke. Thus, both the expansion and the compression ratio vs. eccentricity are depicted in Fig. 10. Based on preliminary studies, it was assumed that eccentricity may be subject to changes in the range from 0 to $15 \mathrm{~mm}$, denoted in Figure 10 as the useful range for engine operation, where the compression stroke does not differ significantly from its initial value, that is important as regards combustion process and any abnormal combustion known as knock.

To show potential benefit from the over-expanded cycles, the expansion/compression ratio was introduced. As one can conclude from Fig. 11, the expansion to compression ratio $(\mathrm{ER} / \mathrm{CR})$ increases with increase in the eccentricity.

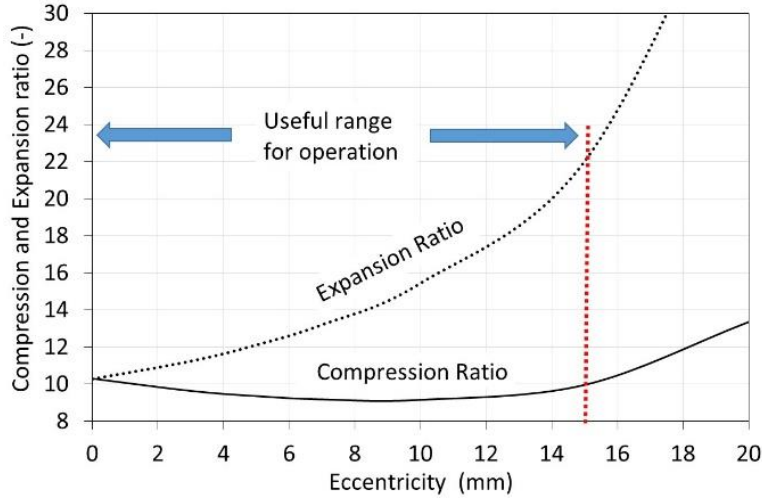

Fig. 10. Expansion and compression ratio vs. eccentricity

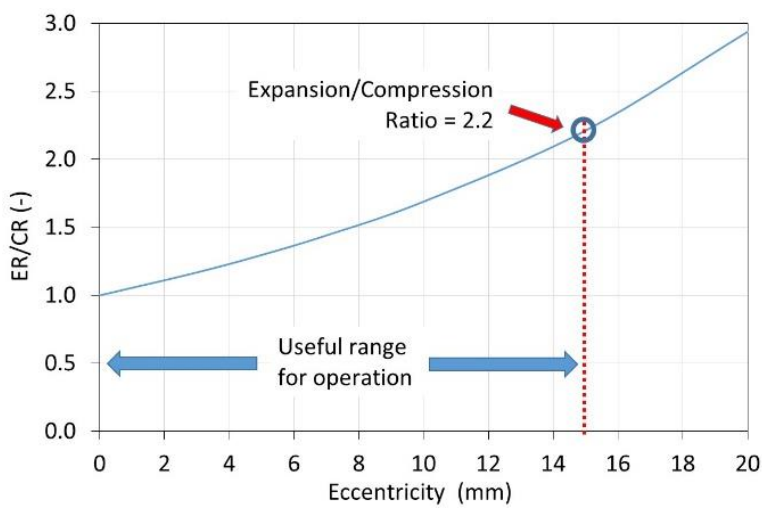

Fig. 11. Expansion to compression ratio vs. eccentricity

The maximum for the eccentricity is limited by the power drop generated by the engine. As shown in Fig. 12, additional power generated by the engine increases with increase in eccentricity and indirectly with increase in expansion/compression ratio. As analyzed, the maximum limit for the ER/CR is 2.2, that corresponds to the eccentricity of approximately $15 \mathrm{~mm}$.

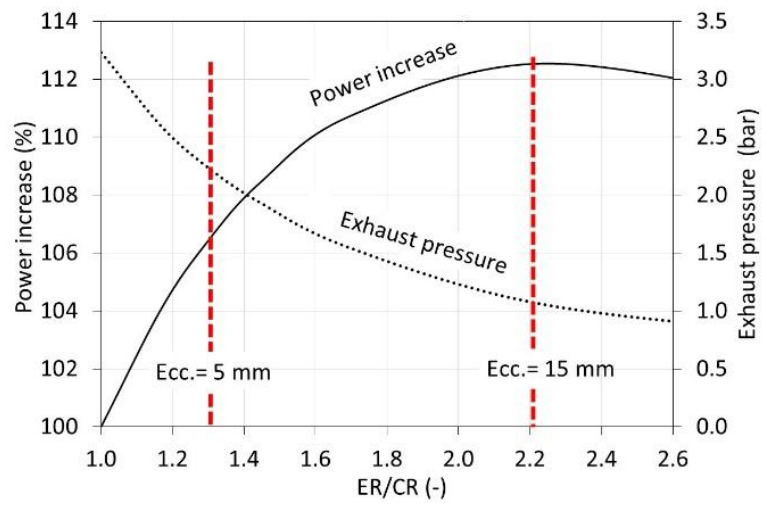

Fig. 12. Power increase and exhaust gas pressure at the end of the expansion stroke

As analyzed plots in Fig. 12, the remarkably low exhaust pressure of approximately 1 bar is observed at the end of the expansion stroke when the exhaust valve gets open for ER/CR of 2.2. This is the additional benefit from applying the over-expanded cycle. The exhaust pressure close to ambient pressure at the exhaust valve opening does not generate a pressure wave in the exhaust manifold, and fur- 
ther, in the exhaust pipeline. Hence, one can conclude that the engine equipped with the over-expanded cycle by Szymkowiak does not require a silencer for dumping exhaust acoustic noise.

\section{Conclusion}

The proposed linkage mechanism invented by Miroslaw Szymkowiak is characterized by the following features:

- expansion/compression ratio (ER/CR) of the engine can be higher 1, which indicates the over-expanded thermodynamic cycle in the engine,
- the maximum of the expansion/compression ratio is 2.2 , which provides the maximum benefit for the engine power,

- by changing the vertical location of the axis of rotation of the eccentric crank, both the expansion and compression ratio can be changed. It can be realized under engine work.

\section{Nomenclature}

BDC bottom dead center

CA crank angle

ER expansion ratio

$\mathrm{CR}$ compression ratio

DI direct injection

TDC top dead center

\section{Bibliography}

[1] PatOP: Single-crankshaft opposed-piston engine http://www.pattakon.com/patop/CommerTS.gif

[2] HILLMAN CAR CLUB OF SOUTH AUSTRALIA INC. https://www.sa.hillman.org.au/TS3.htm

[3] SZYMKOWIAK, M., SZWAJA, S. New concept of a rocker engine - kinematic analysis. Journal of Kones. 2012, 19, 443-449. https://doi.org/10.5604/12314005.1138160

[4] RYCHTER, T.J., TEODORCZYK, A., STONE, C.R. A theoretical study of a variable compression ratio turbocharged diesel engine. Proceedings of the Institution of Mechanical Engineers, Part A: Journal of Power and Energy. 1992, 206(4), 227-238.

https://doi.org/10.1243/PIME_PROC_1992_206_039_02

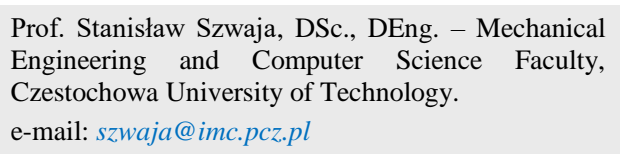

[5] RYCHTER, T.J., TEODORCZYK, A. VR/LE engine with variable R/L during a single cycle. SAE Technical Paper 850206. 1985. https://doi.org/10.4271/850206

[6] KOZAK, W. Crank and rocker piston assembly. Combustion Engines. 2013, 152(1), 10-27.

https://doi.org/10.19206/CE-117009

[7] MAGRYTA, P., PIETRYKOWSKI, K., BIAŁY, M. et al. The influence of load distribution in kinematic constraints of connecting rod on the results of the stress simulation. Combustion Engines. 2017, 170(3), 84-87. https://doi.org/10.19206/CE-2017-313

Mirosław Szymkowiak, MSc. - alumnus from AGH - University of Science and Technology. Engineer in his own enterprise.

e-mail: lfp-ztg@lfp-ztg.pl 